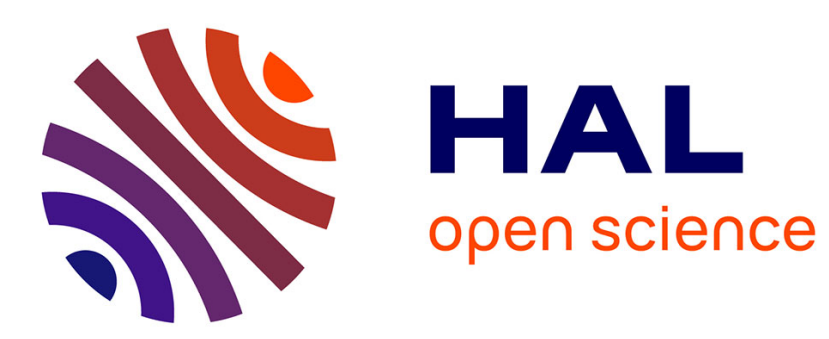

\title{
HIGH PRESSURE N2O LASER : DISCHARGE PROPERTIES, GAIN AND SPECTRA
}

\author{
A. Ionin, M. Kelner, A. Lobanov, D. Okhrimenko, D. Sinitsin, A. Suchkov
}

\section{To cite this version:}

A. Ionin, M. Kelner, A. Lobanov, D. Okhrimenko, D. Sinitsin, et al.. HIGH PRESSURE N2O LASER : DISCHARGE PROPERTIES, GAIN AND SPECTRA. Journal de Physique IV Proceedings, 1991, 01 (C7), pp.C7-729-C7-735. 10.1051/jp4:19917197 • jpa-00250877

\section{HAL Id: jpa-00250877 https://hal.science/jpa-00250877}

Submitted on 1 Jan 1991

HAL is a multi-disciplinary open access archive for the deposit and dissemination of scientific research documents, whether they are published or not. The documents may come from teaching and research institutions in France or abroad, or from public or private research centers.
L'archive ouverte pluridisciplinaire HAL, est destinée au dépôt et à la diffusion de documents scientifiques de niveau recherche, publiés ou non, émanant des établissements d'enseignement et de recherche français ou étrangers, des laboratoires publics ou privés. 


\title{
HIGH PRESSURE $\mathrm{N}_{2}$ O LASER: DISCHARGE PROPERTIES, GAIN AND SPECTRA
}

A.A. IONIN, M.S. KELNER, A.N. LOBANOV, D.B. OKHRIMENKO, D.V. SINITSIN and A.F. SUCHKOV

P.N. Lebedev Physics Institute, USSR Acad. Sci, Leninsky Prosp. 53, Moscow 117924, USSR

\begin{abstract}
The influence of pressure, temperature, composition and components ratio of laser mixture on the discharge properties, gain and lasing parameters of pulsed electron beam controlled discharge $\mathrm{N}_{2} \mathrm{O}$ laser with the output energy more then $100 \mathrm{~J}$ and efficiency about $10 \%$ has been studied experimentally and theoretically. The exoitation effioiency in EBCD and relaxation constant of $\mathrm{N}_{2} \mathrm{O}$ laser levels have been estimated.
\end{abstract}

\section{Introduction.}

Among the electric-discharge IR lasers the $\mathrm{N}_{2} \mathrm{O}$ lasers with $\lambda_{\text {las }} \approx$ $10.9 \mu \mathrm{m} / 1 /$ are inferior to $\mathrm{CO}$ and $\mathrm{CO}_{2}$ lasers only as regards power and efficiency. The power of low-pressure $\mathrm{CW} \mathrm{N}_{2} \mathrm{O}$ lasers is, however, 4-6 times lower than the power of $\mathrm{CO}_{2}$ laser, and the effioiency $\leq 3 \%$. The energy of a TEA $\mathrm{N}_{2} \mathrm{O}$ laser did not exceed, up to the beginning of our experiments, one Joule, and the efficiency $\leq 2 \%$. The application of eleotron-beam-controlled discharge ( $\mathrm{EBCD}$ ) pumping method in $/ 2 /$ did not make it possible to make a powerful and effective $\mathrm{N}_{2} \mathrm{O}$ laser $(0.6 \mathrm{~J}, 2 \mathrm{~J} / \mathrm{l} \cdot \mathrm{atm}, 0.3 \%)$. This paper reports the results of the experimental and theoretical studies of a powerful and efficient EBCD $\mathrm{N}_{2} \mathrm{O}$ laser with energy and efficiency essentially exceeding the known values for eleotric discharge $\mathrm{N}_{2} \mathrm{O}$ lasers.

\section{Experimental setup.}

The experiments on investigations of output power characteristics, discharge, gain and spectral properties of the active medium of high power pulsed EBCD $\mathrm{N}_{2} \mathrm{O}$ laser were carried out at the two EBCD laser installations with active volumes $-2 \mathrm{I}\left(3.6 \times 4.2 \times 140 \mathrm{~cm}^{3}\right)$ and $\sim 10 \mathrm{I}$ $\left(10 \times 10 \times 100 \mathrm{~cm}^{3}\right) / 3 /$. Electron beam current dencity (in both 
installations, was in the range $10-20 \mathrm{~mA} / \mathrm{cm}^{2}$, the discharge current pulse duration was 20-50 $\mathrm{s}$. These laser devices were able to operate both independently and as "master osoillator - laser amplifier " system $/ 4 /$.

3. Discharge properties and laser energy characteristics.

Fig.1 demonstrates the dependenoe of input energy on reduoed

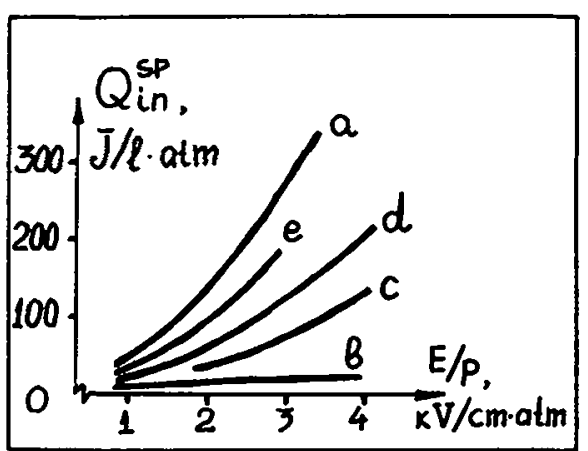

Fig.1. Specirio input energy $Q: P$ vs reduced initial in field $\mathrm{E} / \mathrm{P}$.

Mixture $\mathrm{Nz}: \mathrm{NzO}: \mathrm{CO}: \mathrm{CO}: \mathrm{He}=$ $1: 0: 0: 0: 1(\mathrm{a})$,

20:3:0:0:27(b),

10:3:10:0:27 (o),

$0: 3: 20: 0: 27(d)$,

$5: 0: 0: 1: 6(e)$. initial field $E / P$ in active medium (gas pressure $=0.25 \mathrm{~atm}$.) of EBCD $\mathrm{N}_{2} \mathrm{O}$ laser. The addition of a small amount of $\mathrm{N}_{2} \mathrm{O}$ into the mixture of $\mathrm{N}_{2}$ and He decreased, by more than an order of magnitude, the energy input into discharge (Fig.1, lines $a$ and $b$ ). The decrease in the input energy is connected with the decrease of the eleotron concentration in FBCD due to dissociative attachment of electrons /5/:

$$
\mathrm{N}_{2} \mathrm{O}+\mathrm{e} \Rightarrow \mathrm{N}_{2}+\mathrm{O}^{-}
$$

The energy input in the EBCD was increased considerably when part of $\mathrm{N}_{2}$ was substituted for CO (Fig.1, line 0 ). The increase of input energy can be due to a process of associative detachment of eleotrons /5/:

$$
\mathrm{O}^{-}+\mathrm{CO} \Rightarrow \mathrm{CO}_{2}+\mathrm{e}
$$

The largest energy input in the gas mixtures containing $\mathrm{N}_{2} \mathrm{O}$ was realized when $\mathrm{N}_{2}$ was fully substituted for CO (Fig.1, line d). When the value of parameter $E / P$ was lixed, the energy input was lower than that known for typioal gas mixtures of EBCD $\mathrm{CO}_{2}$ lasers with $50 \%$ concentration of $\mathrm{He}$ (Fig.1, Iine e).

The power and efficienoy of EBCD $\mathrm{N}_{2} \mathrm{O}$ laser depended essentially on the composition of the laser mitture. The influence of atomic (He, Ar, Xe) and molecular $\left(\mathrm{N}_{2}, \mathrm{CO}\right)$ gas concentrations on the output energy and efficiency of the EBCD $\mathrm{N}_{2} \mathrm{O}$ laser was studied at the experimental conditions: the electron beam current denoity $\sim 20 \mathrm{~mA} / \mathrm{cm}^{2}$, the EBCD discharge duration $\sim 20 \mu \mathrm{s}$, the active volume $\sim 2 \mathrm{I}$. The laser cavity of $3.5 \mathrm{~m}$ length was created by two copper mirrors (one plat and one concave spherical with radius of curvature $10 \mathrm{~m}$ ). The radiation was extracted by means of NaCI flat plate inserted into laser cavity and slightly disaligned from its optical axis. 
The addition of $\mathrm{CO}$ in the laser mixture $\mathrm{N}_{2} \mathrm{O}: \mathrm{N}_{2}$ : He or the total substitution of $\mathrm{N}_{2}$ for $\mathrm{CO}$ increased not only the energy input into FBCD, but the output energy and efficiency of the $\mathrm{N}_{2} \mathrm{O}$ laser. The Iaser

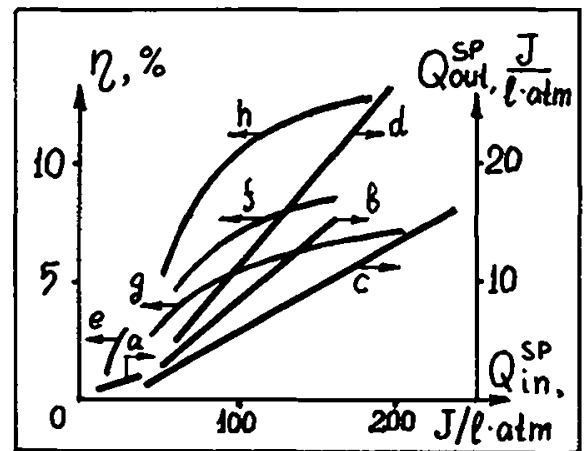

Fig.2.Specific output $Q_{\text {out }}^{\text {sp }}$ and efficiency $\eta$ vs cpecifio input energy $Q_{i}^{s p}$.
$\mathrm{N}_{2}: \mathrm{N}_{2} \mathrm{O}: \mathrm{CO}: \mathrm{CO}_{2}: \mathrm{He}=$ 20:3:0:0:27 (a,e), $10: 3: 10: 0: 27(b, f)$, $0: 3: 20: 0: 27(0, g)$, $5: 0: 0: 1: 6(\alpha, h)$. Free-muning mode. energy $\sim 8 \mathrm{~J}$ (specific output $\sim 16 \mathrm{~J} / \mathrm{I} \cdot \mathrm{atm}$ ) and efficiency $\sim 7 \%$ were obtained in laser, acting on the gas mixture $\mathrm{N}_{2} \mathrm{O}: \mathrm{CO}$ : $\mathrm{He}=3: 20: 27$ (Fig.2, Iines $\mathrm{c}$ and $\mathrm{g})$. The efficiency was increased up to $9 \%(6.5 \mathrm{~J}$, $13 \mathrm{~J} / \mathrm{l} \cdot \mathrm{atm})$ by using lour-component gas mixture $\mathrm{N}_{2} \mathrm{O}: \mathrm{CO}: \mathrm{N}_{2}: \mathrm{He}=3: 10: 10: 27 \quad(50 \%$ of $\mathrm{N}_{2}$ was replaced by $\mathrm{CO}$ ) characterized by less input energy ( Fig.2, lines b and 1 ). The efficiency was also increased up to $11 \%$ by cooling of gas mixture dow to $220 \mathrm{~K}$.

For three-component gas mixture $\mathrm{N}_{2} \mathrm{O}$ : $\mathrm{CO}$ : He that contained $50 \%$ of He (the total gas pressure $\mathrm{p}=0.25 \mathrm{~atm}$.) the dependence of laser output energy on the $\mathrm{N}_{2} \mathrm{O}$ to $\mathrm{CO}$ concentrations ratio was investigated.

The output energy maximum for the parameter $\mathrm{E} / \mathrm{P} \sim 10 \mathrm{kV} / \mathrm{cm} \cdot \mathrm{atm}$ was obtained at the ratio $\mathrm{N}_{2} \mathrm{O}: \mathrm{CO}$ nearly 5:33. The laser output energy without $\mathrm{He}$ in the gas mixture ( mixture $\mathrm{N}_{2} \mathrm{O}: \mathrm{CO}: \mathrm{He}=3: 33: \mathrm{X}$ with total pressure $\mathbf{p}=0.25 \mathrm{~atm}$ ) was not higher than $5 \mathrm{~J}$. The optimum concentration of $\mathrm{He}$ in $\mathrm{N}_{2} \mathrm{O}$ laser mixture $\mathrm{N}_{2} \mathrm{O}: \mathrm{CO}: \mathrm{He}$ was $\mathrm{X} \sim 30 \%$. The maximum specifio output energy of $\operatorname{ECD} \mathrm{N}_{2} \mathrm{O}$ laser with gas mixture $\mathrm{N}_{2} \mathrm{O}$ : $\mathrm{CO}: \mathrm{He}=5: 33: 16.5$ and $\mathrm{E} / \mathrm{P}=10 \mathrm{kV} / \mathrm{cm} \cdot \mathrm{atm}$ was $30 \mathrm{~J} / \mathrm{l} \cdot \mathrm{atm}$ at the efrioiency $9 \%$.

The usage of $\mathrm{Ar}$ and $\mathrm{Xe}$ as the partial substitute of $\mathrm{He}$ in the laser mixture of $\mathrm{EBCD} \mathrm{CO}_{2}$ lasers was permited to inorease the pumping and the laser generation power with the same eleotron beam current density $/ 6 /$, beoause the ionization degree of Ar and Xe is more than that of He. The influence of $\mathrm{Ar}$ and $\mathrm{Xe}$ on the $\mathrm{FBCD} \mathrm{N}_{z} \mathrm{O}$ laser output characteristios was investigated on the laser gas mixture $\mathrm{N}_{2} \mathrm{O}: \mathrm{CO}:$ (He+ $A r+\mathrm{Xe}$ ) $=5: 33: 16.5$. When part of He (up to $6 \%,[\mathrm{Xe}]=0$ ) was replaced by Ar a low increase of output laser energy (up to $10 \%$ ) was obtained. The further diluting of $\mathrm{He}$ by $\mathrm{Ar} \quad(\mathrm{Xe}]=0)$ led to the sharp deorease of the laser output energy. The addition of Xe to the laser gas mixture led to the decrease of laser output energy.The full 
substitution of $\mathrm{He}$ for $\mathrm{Ar}$ or $\mathrm{Xe}$ led to 6-7 times reduction of EBCD $\mathrm{N}_{2} \mathrm{O}$ laser output energy.

The comparison between energy characteristics of $\mathrm{N}_{2} \mathrm{O}$ lasers acting on gas mixtures with carbon monoxide and without co demonstrated that influenoe of carbon monoxide on laser energy and efficiency was due to the prooess (2). One can see from Fig.2 that there must be optimum proportion between $\mathrm{N}_{2} \mathrm{O}$ and $\mathrm{CO}$ concentration in laser mixture. At the same pumping conditions laser energy and effioiency of $\mathrm{BCD} \mathrm{N}_{2} \mathrm{O}$ laser was about 1.5 times lower than that of EBCD $\mathrm{CO}_{2}$ laser acting on conventional laser mixture $\mathrm{CO}_{2}: \mathrm{N}_{2}: \mathrm{He}=1: 5: 6$ (Fig.2, Iines $d$ and $\mathrm{h}$ ). But it should be pointed out that under experimental conditions the output energy of $\mathrm{CO}_{2}$ laser was 1.5-2 times lower than that of limit magnitude.

The EBCD $\mathrm{N}_{2} \mathrm{O}$ laser generated on several Iines $P(19), P(20), P(24)$ within the spectral band with center wavelength $\sim 10.9 \mu$. At the same pumping conditions EBCD $\mathrm{CO}_{2}$ laser acted on $P(18)$ and $P(20)$ lines ( input energy $200 \mathrm{~J} / \mathrm{l} \cdot \mathrm{atm}$ ). The laser aoting was observed simultaneously on $\mathrm{CO}_{2}$ and $\mathrm{N}_{2} \mathrm{O}$ laser transitions when carbon dioxide was added to the laser gas mixture $\left(\mathrm{N}_{2} \mathrm{O}: \mathrm{CO}_{2}: \mathrm{CO}: \mathrm{N}_{2}: \mathrm{He}=1.5: 1.5: 10: 10:\right.$ 27 ). The number of lines and laser wavelengths depended on input energy, temperature and composition of laser mixture.

Using the optimum laser gas mixture $\mathrm{N}_{2} \mathrm{O}: \mathrm{CO}: \mathrm{He}=5: 33: 16.5$ and the laser installation with active volume 101 we obtained the output laser energy $480 \mathrm{~J}(\mathrm{P}=0.25 \mathrm{~atm} ., \mathrm{E} / \mathrm{P}=10 \mathrm{kV} / \mathrm{cm} \cdot \mathrm{atm}$., speoific Iaser output energy $\sim 30 \mathrm{~J} / \mathrm{l} \cdot \mathrm{atm}$.$) . The maximum efficiency was \sim 9 \%$ with specific input energy $\sim 200 \mathrm{~J} / \mathrm{I} \cdot \mathrm{atm}$. The further input energy increase led to the efficienoy reduction. It may be connected with overheating of the gas mixture and with the de-excitation of the upper laser level by electron strike. When the Iaser gas mixture was oooled to the temperature $\sim-30^{\circ} \mathrm{C}$ ( the relative gas density $\mathrm{N}=0.3$ Amagat), the output Iaser energy grew up to $106 \mathrm{~J}$ (speoific output energy $36 \mathrm{~J} / 1$. Amagat, efficiency $10 \%$ ). This growth was determined by the decrease of the upper laser level relaxation rate and by the reduction of the $\mathrm{N}_{2} \mathrm{O}$ moleoules dissociation rate when cooling laser gas mixture in the EBCD /7/. The Pree-running laser action appeared on several transitions from $P(15)$ to $P(24)$ depending on laser gas temperature and speoific input energy.

4. Gain and speotra.

The theoretical small signal gain (SSG) calculations for laser mixture $\mathrm{N}_{\mathrm{z}} \mathrm{O}$ : $\mathrm{CO}$ : He excited in EBCD have been made on the base of 
vibrational temperature model $/ 8,9 /$. The corrected values of $\mathrm{V}-\mathrm{V}$ and $V-T$ rate constants $/ 10 /$ and Ainstain's coefficient $/ 11 /$ have been taken for the $\left(0,0^{\circ}, 1-1,0^{\circ}, 0\right)$ transition of $\mathrm{N}_{2} \mathrm{O}$ molecule. As there is not a selfconforming set of electron strike excitation crosseotions for vibrational $\mathrm{N}_{2} \mathrm{O}$ moleoule levels, that needs to SSG calculations, experimental values of eleotric rield $\mathrm{E} / \mathrm{P}$ and current $\mathrm{I}$ in $\mathrm{EBCD}$ and adapting parameter $\delta$ ( $\mathrm{EBCD}$ energy part coming to $\mathrm{CO}$ and $\mathrm{N}_{2} \mathrm{O}$ excitation) have been used.

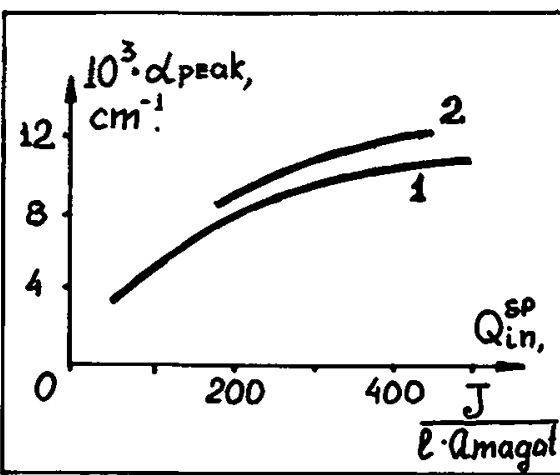

Fig.3. SSG peak value apeak VS specific input energy in EBCD $Q_{i n}$. $\mathrm{N} 20: 00: \mathrm{He}=$ $1: 6: 3,{ }^{\text {in }} \mathrm{P}=.25$ Amagat, $\mathrm{P}(20)$ line, $\mathrm{T}=293 \mathrm{~K}(1), 260 \mathrm{~K}(2)$.

The SSG peak value dependenoe on specific energy input in $\mathrm{BBCD}$ presented at the 1ig.3. If $Q_{i n}^{\text {sp }}>300 \mathrm{~J} / \mathrm{l}$ - Amagat one can see saturation of SSG at the temperature $\mathrm{T}=$ $293 \mathrm{~K}$ (Iine 1) called by laser mixture heating in EBCD. The initial laser gas cooling up to $T=260 \mathrm{~K}$ increased the $\mathrm{SSG}$ peak value to $1.15 \cdot 10^{-2} \mathrm{~cm}^{-1}$ (line 2). The comparison of experimental and caloulated SSG values permited to define dependence o $\nabla S E / P$, that may be approximated by expression $\delta=0.675+0.093 \cdot \lg (E / P-3)$ within $E / P$ range Irom 3 to $8 \mathrm{kV} / \mathrm{om} \cdot \mathrm{atm}$.

The experimental (a) and calculated (b) SSG time histories for the different laser mixture pressures at ixed specific input energy are presented on 1ig.4. With the increase of laser gas pressure the duration of these dependencies back fronts were shorter, that will entail relaxation time reduction of upper $\mathrm{N}_{2} \mathrm{O}$ molecule laser level $\left(0,0^{\circ}, 1\right)$.
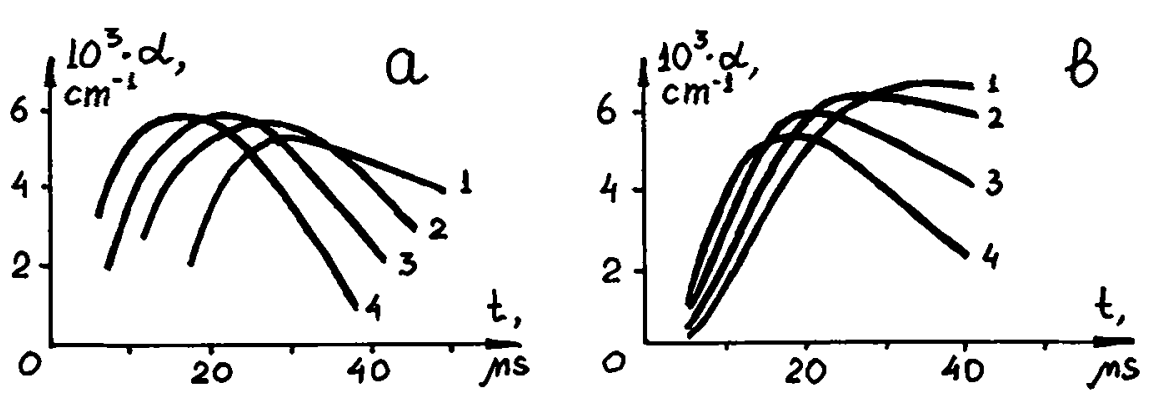

Fig.4. Experimental (a) and theoretical (b) SSG time history for the different laser gas pressures $P$. Mixture $\mathrm{N}_{2} \mathrm{O}: \mathrm{CD}: \mathrm{He}=1: 6: 3, Q_{\text {in }}=150$ $\mathrm{J} / \mathrm{l} \cdot \mathrm{atm}, \mathrm{T}=293 \mathrm{~K} . \mathrm{P}=.07 \mathrm{~atm}(1), .125 \mathrm{~atm}(2), .25 \mathrm{~atm}(3)$, and $.4 \mathrm{~atm}(4)$. 
Experimental relaxation constant was estimated about $4 \cdot 10^{2}$ torr ${ }^{-4} \cdot \mathrm{s}^{-1}$. The maximum values of calculated SSG (fig. 4 b) are some higher than that measured in experiments (fig.4 a) and the rate of experimental lines lowering from time more than $20 \mu \mathrm{s}$ is stronger than the calculated one. It may be called by existence of eleotrio field inhomogeneities and thermal gas away flying in EBCD, that are not taken into calculations.

The speotral SSG peak value distribution through vibrational-rotational lines of $\mathrm{N}_{2} \mathrm{O}$ molecules $\mathrm{P}$ - and $\mathrm{R}$ - branches, getting in our experiments, presented at the 1ig.5. High values of SSG

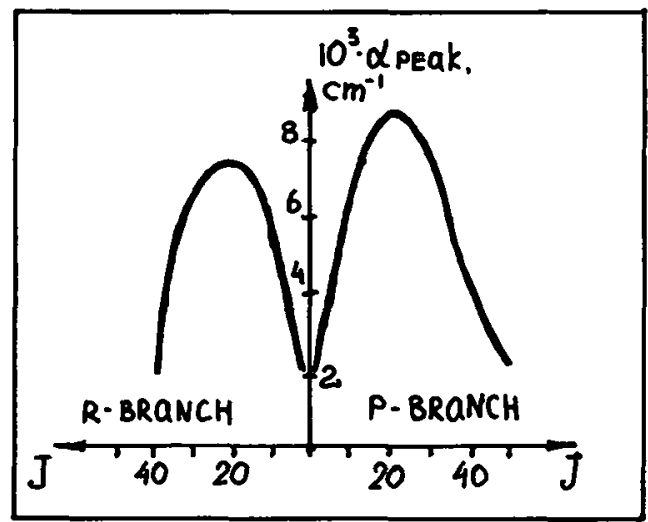

Fig.5. SSG peak values spectral distribution. Mixture $\mathrm{N2O}: \mathrm{CO}: \mathrm{He}=$ $1: 6: 3, P=.4 \mathrm{~atm}, Q_{i n}^{2 P}=150 \mathrm{~J} / \mathrm{I} \cdot \mathrm{atm}$ $\mathrm{T}=293 \mathrm{~K}$. Seleotive laser mode.

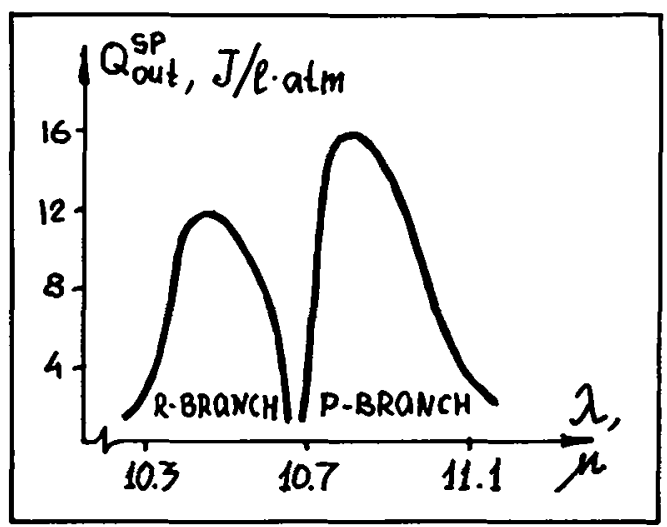

Fig.6. Specifio output spectral distribution. Mixture $\mathrm{N2O}: \mathrm{CO}: \mathrm{He}=$ $1: 6: 3, P=.4 \mathrm{~atm}, Q_{i n}^{8 P}=150 \mathrm{~J} / \mathrm{I} \cdot \mathrm{atm}$ $\mathrm{T}=293 \mathrm{~K}$. Seleotive laser mode.

in EBCD $\mathrm{N}_{2} \mathrm{O}$ laser and strong exceeding of pumping energy over threshold one $\left(\alpha_{t h}{ }^{\sim 10^{-9}} \cdot \mathrm{cm}^{-1}\right)$ permited us to expend lasing vibrationalrotational lines row to $P(2)-P(46)$ and $R(47)-R(2)$. The maximum specifio output was $\sim 16 \mathrm{~J} / \mathrm{I} \cdot \mathrm{atm}$ on $\mathrm{P}$-branoh (Iine $\mathrm{P}(18)$ ) and $\sim 12 \mathrm{~J} / \mathrm{I} \cdot \mathrm{atm}$ on R-branoh ( line $\mathrm{R}(20)$ ) (1ig.6).

REFERENCES.

1. C.K.N.Patel, App1. Phys. Letts, vol.6, p12, 1970.

2. F.O'Neill, W.T. Whitney, Appl. Phys. Letts, vol.28, p.539, 1976.

3. N.G.Basov, V.G.Bakaev at al, J.of Techn. Phys, vol.55, p.326, 1985.

4. V.Yu.Ananiev at al, Quantum Eleotronics, vol.12, p.1660, 1985.

5. J.M.Warman at al, J. Chem. Phys., vol.57, p.2702, 1972.

6. A.P.Averin at al, Quantum Electronios, vol.8, p.2063, 1981.

7. I.S.Pollack, "Modeling And Calculation Methods For Low Temperature 
Plasmas", Science, Moscow, 1974.

8. K.Smit, R.Thomson, "Numerical Modeling of Gas Lasers", Peace, Mosoow, 1981.

9. Yu.A.Kulagin, Transactions of Lebedev Physics Institute, vol.107, p.110, 1979.

10.A.P.Zuev, Chem. Phys., vol.7, p.923, 1983.

11.R.A.McClatchey at al, AFCRU-TR-73-0096, Environmental res. papers, vol.434, p.78, 1973. 